\title{
Influence of Aluminum Silicate and Cerium (IV) Oxide Nanofluid on Pool Boiling Characteristics
}

\author{
Yoganand Kumaravelu, ${ }^{1}$ Vasanthkumar Periyathambi $\mathbb{D}^{1}{ }^{1}$ Poongundran Udhayanan, ${ }^{1}$ \\ Mohanraj Murugesan, ${ }^{2}$ R. Jothi Ramalingam, ${ }^{3}$ Hamad Al-Lohedan, ${ }^{3}$ \\ Dhaifallah M. Al-dhayan, ${ }^{3}$ and Ishwarya Komalnu Raghavan $\mathbb{D}^{4}$ \\ ${ }^{1}$ Department of Mechanical Engineering, SRM Institute of Science and Technology, Ramapuram, Chennai 600089, India \\ ${ }^{2}$ Department of Mechanical System Design Engineering, Seoul National University of Science \& Technology, \\ Seoul-01811, Republic of Korea \\ ${ }^{3}$ Chemistry Department, College of Science, King Saud University, P.O. Box. 2455, Riyadh 11451, Saudi Arabia \\ ${ }^{4}$ Department of Electromechanical Engineering, Faculty of Manufacturing, Institute of Technology, Hawassa University, \\ Hawassa, Ethiopia
}

Correspondence should be addressed to Vasanthkumar Periyathambi; pvasanthme@gmail.com

Received 2 December 2021; Accepted 27 December 2021; Published 11 February 2022

Academic Editor: V. Mohanavel

Copyright (C) 2022 Yoganand Kumaravelu et al. This is an open access article distributed under the Creative Commons Attribution License, which permits unrestricted use, distribution, and reproduction in any medium, provided the original work is properly cited.

\begin{abstract}
A study into pool boiling heat transfer with nanofluids particularly aluminum silicate and cerium (IV) oxide was used to prepare nanofluids. A review of existing nanofluid implementations done previously in multiple literature and research journals was taken into consideration while determining their effects as nanoparticles in necessary base fluids. The nanofluids were prepared with two-step method by dispersing $\mathrm{Al}_{2} \mathrm{SiO}_{5}$ and $\mathrm{CeO}_{2}$ nanopowders in water and were analyzed at base temperatures of $50-75^{\circ} \mathrm{C}$ and peak flux readings taken at saturation temperature. An inference between these and surface modifications due to settlement of nanoparticles on heater surface was studied by SEM imaging, and dispersion was studied with TEM imaging. The volume concentrations of $\mathrm{Al}_{2} \mathrm{SiO}_{5}$ and $\mathrm{CeO}_{2}$ nanofluids are varied from $0.1 \% \leq \varphi \leq 0.3 \%$. Readings taken at temperatures varied by $5^{\circ} \mathrm{C}$ between $50^{\circ} \mathrm{C}$ to $75^{\circ} \mathrm{C}$ and at $100^{\circ} \mathrm{C}$. The improvement of $q^{\prime \prime}$ for $\mathrm{Al}_{2} \mathrm{SiO}_{5} / \mathrm{H}_{2} \mathrm{O}$ and $\mathrm{CeO}_{2} / \mathrm{H}_{2} \mathrm{O}$ nanofluids is about $120.5 \pm 0.6 \%$ in PHF over water as base fluids for $0.3 \%$ volume concentration solutions.
\end{abstract}

\section{Introduction}

Boiling heat transfer has always been a powerful energy extradition technology which persuades the way in achieving milestones in the advancement of the futuristic technologies. The ameliorations in the field of nanotechnology have gone hand-in-hand with almost all the fields, and the enhancement by implementing it in the boiling heat transfer has exhibited enormous increase in the efficiency of the process and has played a role in the elevation of the reliability of the process by increasing various factors that are need of the hour. Our experiments had us spectate that the PHF has inclined to a steep level upon addition of minimal quantity of nanoparticles. Nanofluids were prepared with the aid of dispersion of the nanoparticles of the order 10-50 nm which gave the increase of density of fluid and also high specific surface-area that paves the way to higher heat transfer between surface and fluids. It also grants acclimation of properties such as thermal conductivity and wettability by varying the concentrations. Our experiments were conducted based on pool boiling, and the results were focused mainly on uplifting of the PHF using nanofluids as the base fluid [1]. All these property enrichments are noticed because the high surface area of the nanoparticle and their enhanced thermal properties. Pool boiling is mode of the boiling phenomenon in which fluid is stationary with respect to heating surface in the beginning; vapor is spawned at a superheated wall that is 


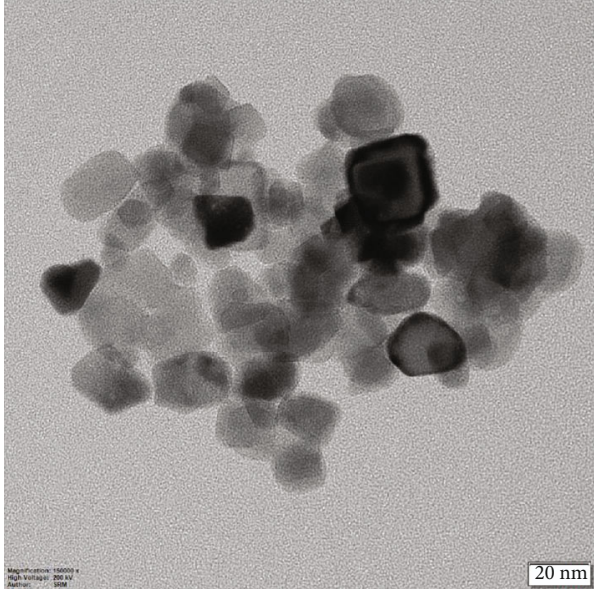

(a)

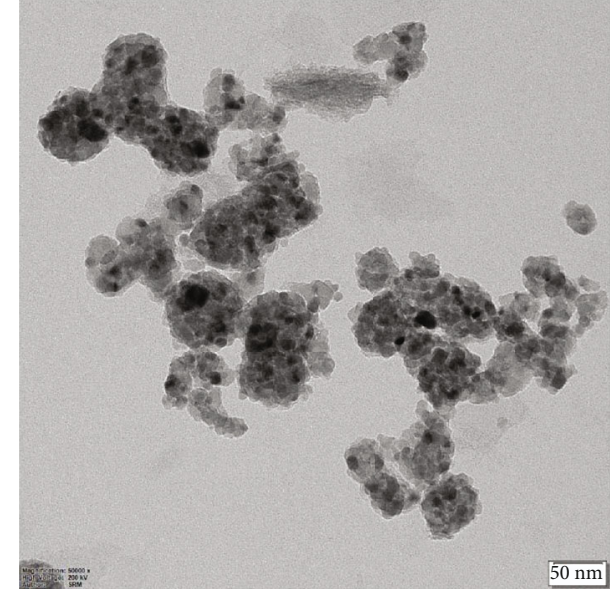

(b)

FIgURE 1: HRTEM image of dried nanoparticles after dispersion in water: (a) $\mathrm{CeO}_{2}$ nanoparticle and (b) $\mathrm{Al}_{2} \mathrm{SiO}_{5}$ nanoparticle.

tiny compared to the dimensions of the pool of ostensibly dormant liquid in which it is intent. In our experiments as cited in several papers, we use Ni-Chrome (80-20\% composition) wire as the heating element through a set of platinum wire which has minimal resistance and anticorrosive in nature, and electricity is supplied. The bubbles formed by the cause are captured, and the certain parameters were calculated on the nucleation site, and the corresponding density with the diameter of the bubble that is formed when different nanofluid is applied $[2,3]$. The existence of a vermicular structure in $\mathrm{CuO}$ nanoparticles contributes to the particles' wear resistance and improved lubrication [4].

The literature demonstrated that a variety of parameters could affect the performance of pool boiling of nanofluids as represented by the pool boiling heat transfer coefficient including the amount of nanoparticle loading, the size of nanomaterials, the roughness of the heater, the thickness of the thermally insulating nanolayer, and the time of boiling. A number of parameters may directly affect the behavior of bubbles, including the density of nucleation sites, bubble diameter, bubble frequency, bubble waiting time, and growth time, considered as essential boiling parameters that might influence the boiling performance of pools.

It has been determined that cerium oxide nanoparticles can be considered as an attractive nanomaterial based on the data from all published experimental studies. They are inexpensive, have excellent chemical and physical properties, are nontoxic compared to other metal oxide powders, and are available as a readily available material. As acclaimed in various papers that the alumina [5] and silica nanoparticles [6] tend to increase the peak heat flux of the heating element, we have proposed to use a complex aluminum silicate which has the properties, and in addition to that, cerium was also employed for exhibiting high electron conductivity and also has an increased thermal conductivity due to its valence of electrons.
TABLE 1: Volume concentration values with respective weights.

\begin{tabular}{lcccc}
\hline $\begin{array}{l}\text { Vol. Conc., } \\
\varphi(\%)\end{array}$ & Material & $\begin{array}{c}\text { Density, } \rho_{n} \\
(\mathrm{~g} / \mathrm{cc})\end{array}$ & $\begin{array}{c}\text { Weight, } \\
W_{n}(\mathrm{~g} / \mathrm{L})\end{array}$ & $\begin{array}{c}\text { Molecular } \\
\text { weight }(\mathrm{g} / \mathrm{mol})\end{array}$ \\
\hline 0.1 & $\mathrm{Al}_{2} \mathrm{SiO}_{5}$ & 1.5 & 0.15 & 162.05 \\
0.2 & $\mathrm{Al}_{2} \mathrm{SiO}_{5}$ & 1.5 & 0.3 & 162.05 \\
0.3 & $\mathrm{Al}_{2} \mathrm{SiO}_{5}$ & 1.5 & 0.465 & 162.05 \\
0.1 & $\mathrm{CeO}_{2}$ & 6.5 & 0.656 & 172.115 \\
0.2 & $\mathrm{CeO}_{2}$ & 6.5 & 1.325 & 172.115 \\
0.3 & $\mathrm{CeO}_{2}$ & 6.5 & 2.01 & 172.115 \\
\hline
\end{tabular}

\section{Materials and Methods}

2.1. Chemical and Reagents. Aluminum silicate $\left(\mathrm{Al}_{2} \mathrm{SiO}_{5}\right.$, 99.9\% purity) and cerium (IV) oxide $\left(\mathrm{CeO}_{2}, 99.9 \%\right.$ purity), which was purchased from Platonic nanotech, were used to prepare nanofluids with DI water used as base fluid. All chemicals were of analytical grade. The average sizes were found to be $50 \mathrm{~nm}$ and $40 \mathrm{~nm}$ for aluminum silicate and cerium (IV) oxide, respectively.

2.1.1. Characterization of Material. The nanoparticles were studied with FTIR, XRD, HRSEM, and HRTEM to get better understanding of material properties and compositions. HRSEM was taken with F E I Quanta FEG 200, HRTEM was taken with JEOL Japan, JEM-2100 Plus, and XRD was done using BRUKER USA D8 Advance, Davinci, with nanoparticles in powder form. HRTEM imaging of nanoparticles was taken after drying then once dispersed in DI water as shown in Figures 1(a) and 1(b).

2.1.2. Preparation of Nanofluids. Two methods are used for preparing nanofluids-one-step and two-step methods. Many researchers have reported that two-step method is most economical way to synthesize nanofluids. The advantage of two-step approach is it is cost-effective and able to produce large volumes of nanofluids. In this work, two- 


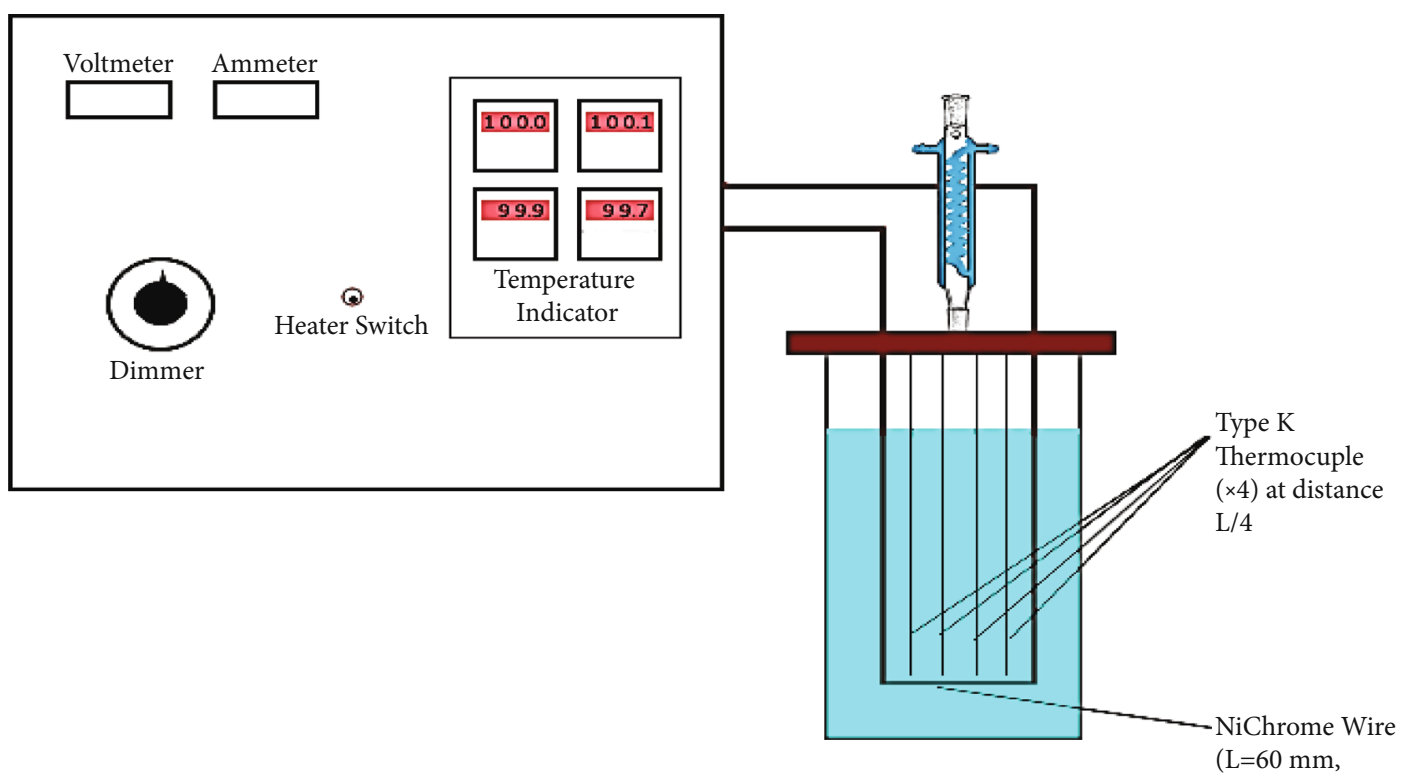

Figure 2: Experimental setup.

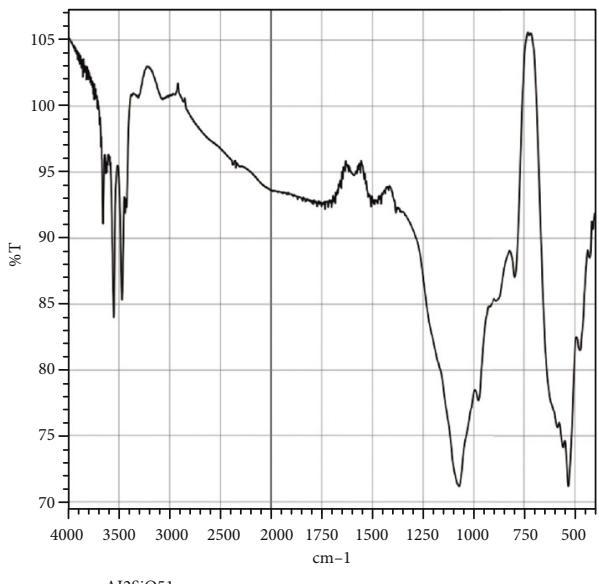

- AI2SiO51

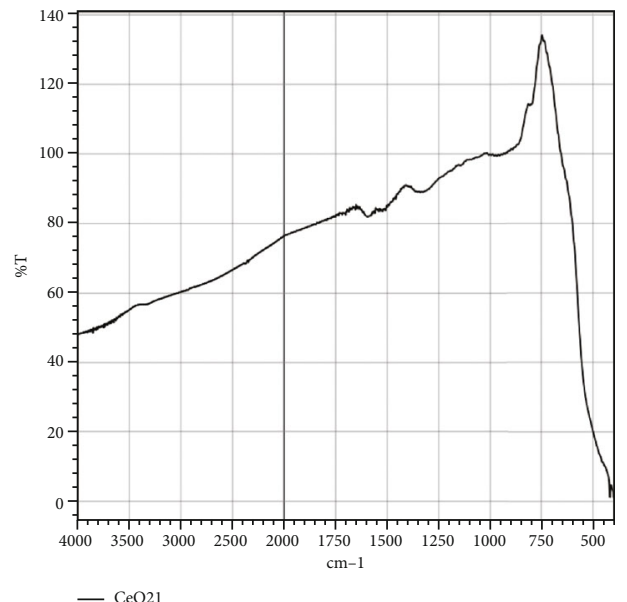

(b)

Figure 3: FTIR spectroscopy: (a) $\mathrm{Al}_{2} \mathrm{SiO}_{5}$ nanoparticle and (b) $\mathrm{C}_{\mathrm{e}} \mathrm{O}_{2}$ nanoparticle.

step method is adopted for preparing aluminum silicate $\left(\mathrm{Al}_{2} \mathrm{SiO}_{5}\right)$ and cerium oxide $\left(\mathrm{CeO}_{2}\right)$ nanofluids. In this process, nanoparticles are prepared and dispersed in the base fluid (distilled water) with or without the help of surfactants by mechanical stirring or ultrasonication methods. The twostep method is widely chosen because the nanoparticles have high surface area and surface energy interactions which tend to aggregate the nanoparticles which are available in dried form.

The following steps are involved in preparation of $\mathrm{Al}_{2} \mathrm{SiO}_{5}$ and $\mathrm{CeO}_{2}$ nanofluids:

Determination of volume concentration $(\varphi)$ for adding to base fluid was done by using the following equation [7]:

$$
\varphi=\left[\frac{\left(W_{n} / \rho_{n}\right)}{\left\{W_{n} / \rho_{n}+W_{\mathrm{bf}} / \rho_{\mathrm{bf}}\right\}}\right] * 100 .
$$

The above equation can be simplified as

$$
W_{n}=\left(\frac{\varphi}{100-\varphi}\right)\left(\frac{\rho_{n}}{\rho_{\mathrm{bf}}}\right) W_{\mathrm{bf}}
$$

By using the above formula, the quantities of nanoparticles to be added are determined as follows in Table 1 .

(i) The measured nanoparticle is added little by little into the base fluid and mechanically stirred for 2 hours. Despite of having extremely small sizes and relatively high kinetic energies resulting from Brownian motion, they do not remain in suspension. With time, nanoparticles settle out of solution under the influence of gravity [8] 


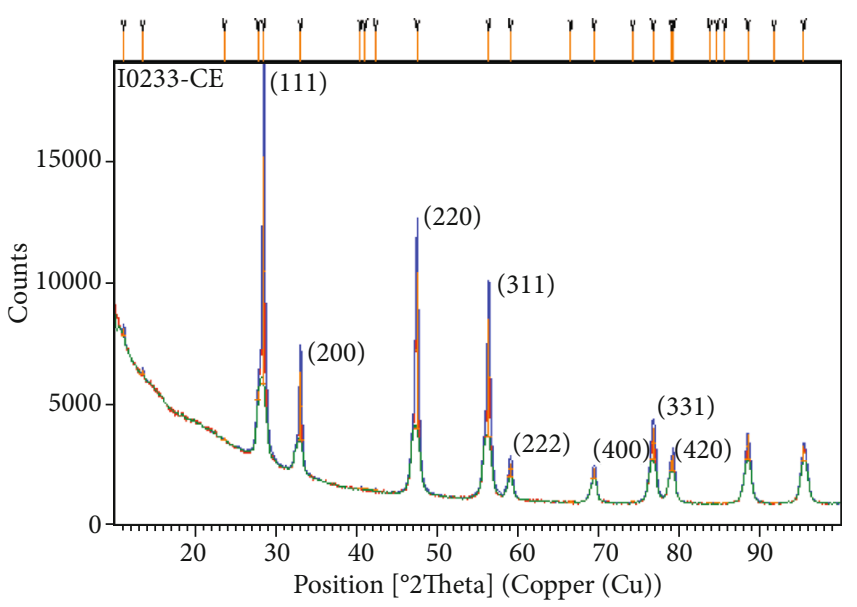

Figure 4: XRD of $\mathrm{CeO}_{2}$ nanoparticle (JCPDS 898436).

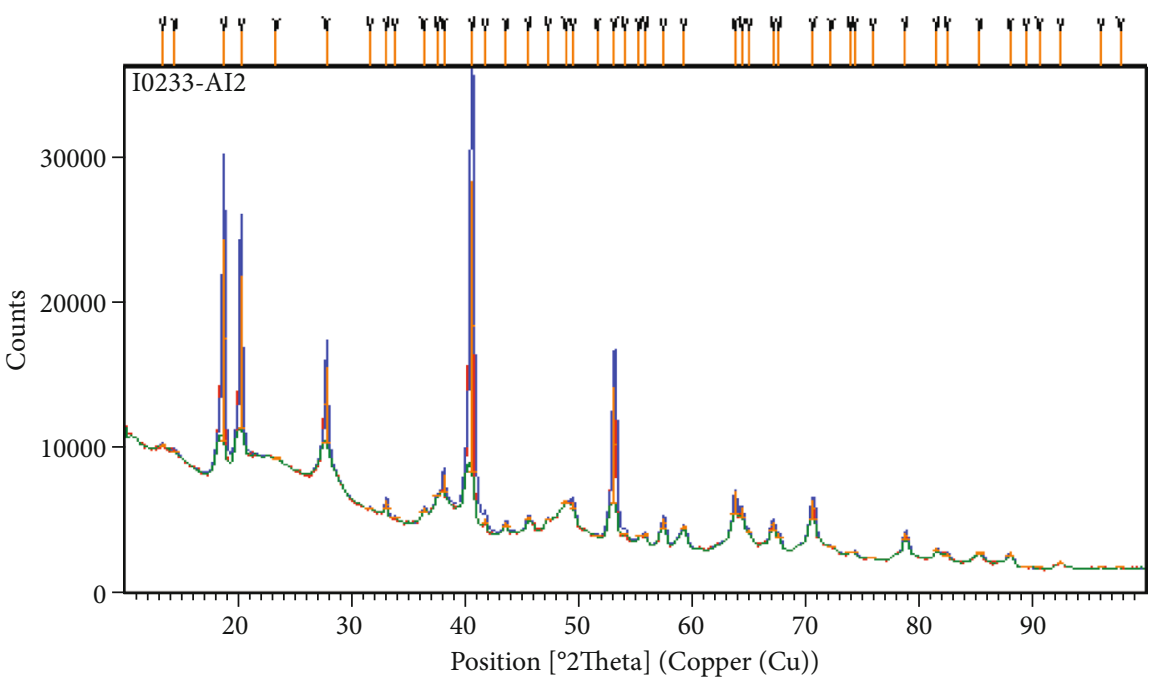

Figure 5: XRD of $\mathrm{Al}_{2} \mathrm{SiO}_{5}$ nanoparticle.

(ii) Hence, after stirring for 2 hours, the nanofluid is subjected to ultrasonication process for 4 hours to ensure uniform dispersion of nanoparticles as well as to prevent the nanoparticles from agglomerating in the base fluid. Many studies show that increase in sonication and stirring time reduces particle clustering

(iii) Nanofluids are considered stable only if no sedimentation takes place over time. Various sedimentation techniques are used to determine long-term stability of wide variety of nanofluids, and we considered simple 24-hour settlement under natural conditions for this study

\section{Experimental Details and Data Analysis}

3.1. Experimental Setup. The setup as shown in Figure 2 consists of a $230 \mathrm{~V}$ AC power supply, hot plate, MI type K thermocouple (4 Nos.), temperature indicators (4 Nos.), jacketed

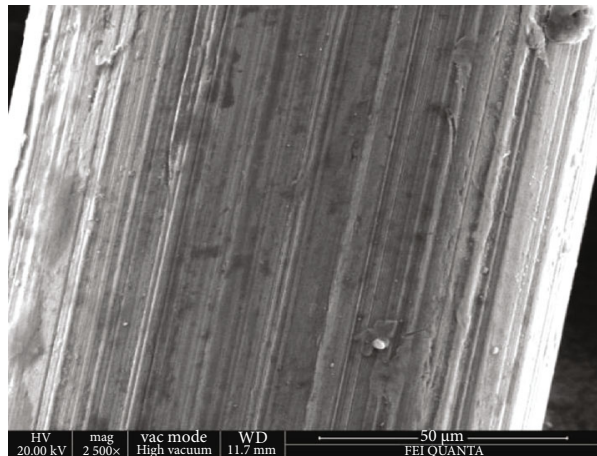

FIGURE 6: SEM image of Ni-Chrome wire (uncoated). condenser, and Ni-Chrome wire of diameter 40 SWG and $60 \mathrm{~mm}$ length which serves as the heater element. To demonstrate this concept, a custom-made glass beaker is made 


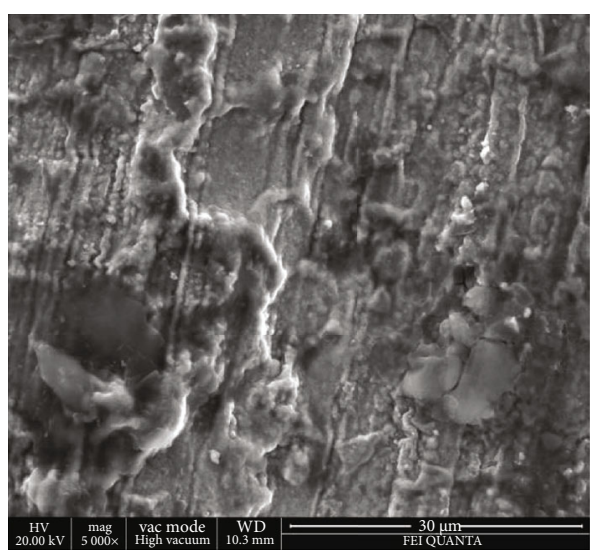

(a)

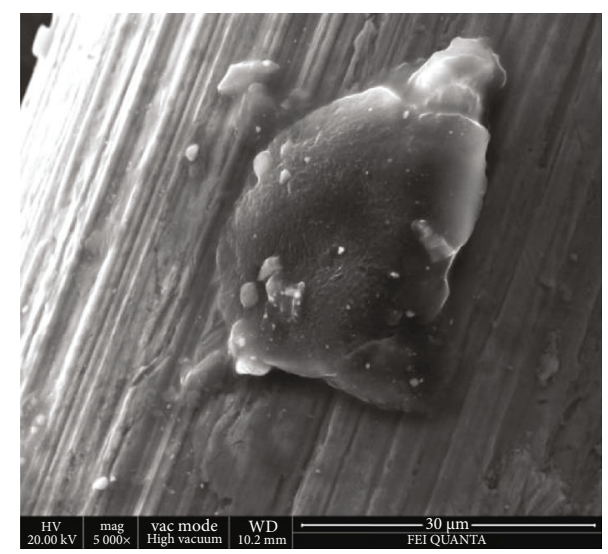

(b)

Figure 7: Surface morphology of heater surface: (a) $0.1 \%$ volume concentration $\mathrm{Al}_{2} \mathrm{SiO}_{5}$ and (b) $0.1 \%$ volume concentration $\mathrm{CeO}$.

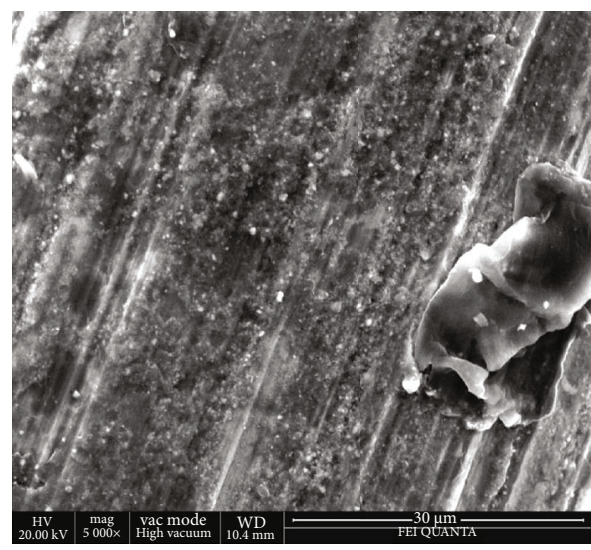

(a)

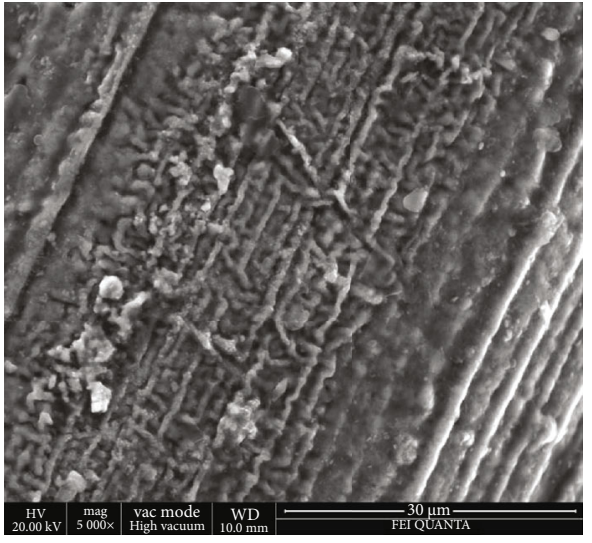

(b)

Figure 8: Surface morphology of heater surface: (a) $0.2 \%$ volume concentration $\mathrm{Al}_{2} \mathrm{SiO}_{5}$ and (b) $0.2 \%$ volume concentration $\mathrm{CeO}$.

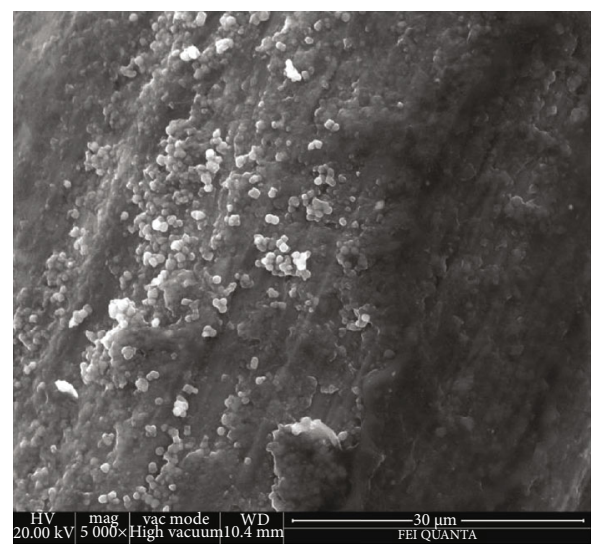

(a)

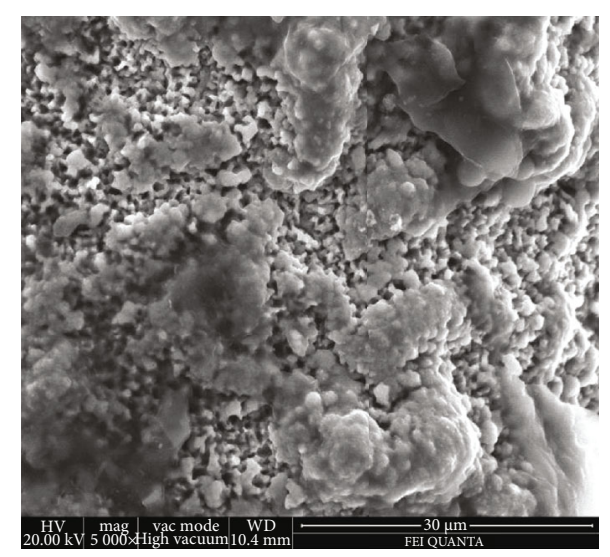

(b)

Figure 9: Surface morphology of heater surface: (a) $0.3 \%$ volume concentration $\mathrm{Al}_{2} \mathrm{SiO}_{5}$ and (b) $0.3 \%$ volume concentration $\mathrm{CeO}$.

for experimenting peak heat flux enhancement in nanofluid. Through the lid of the beaker, voltage sensing wires are connected to two platinum wires which are suspended at ends of the beaker in which the $\mathrm{Ni}$-Chrome wire is connected and current is passed through platinum wire to avoid contact resistance with test specimen. Hot plate is used to heat up to the saturation temperature $T_{\text {sat }}\left(100^{\circ} \mathrm{C}\right.$ for water $)$ of fluid, at $1 \mathrm{~atm}$, while bulk temperature was being monitored with 


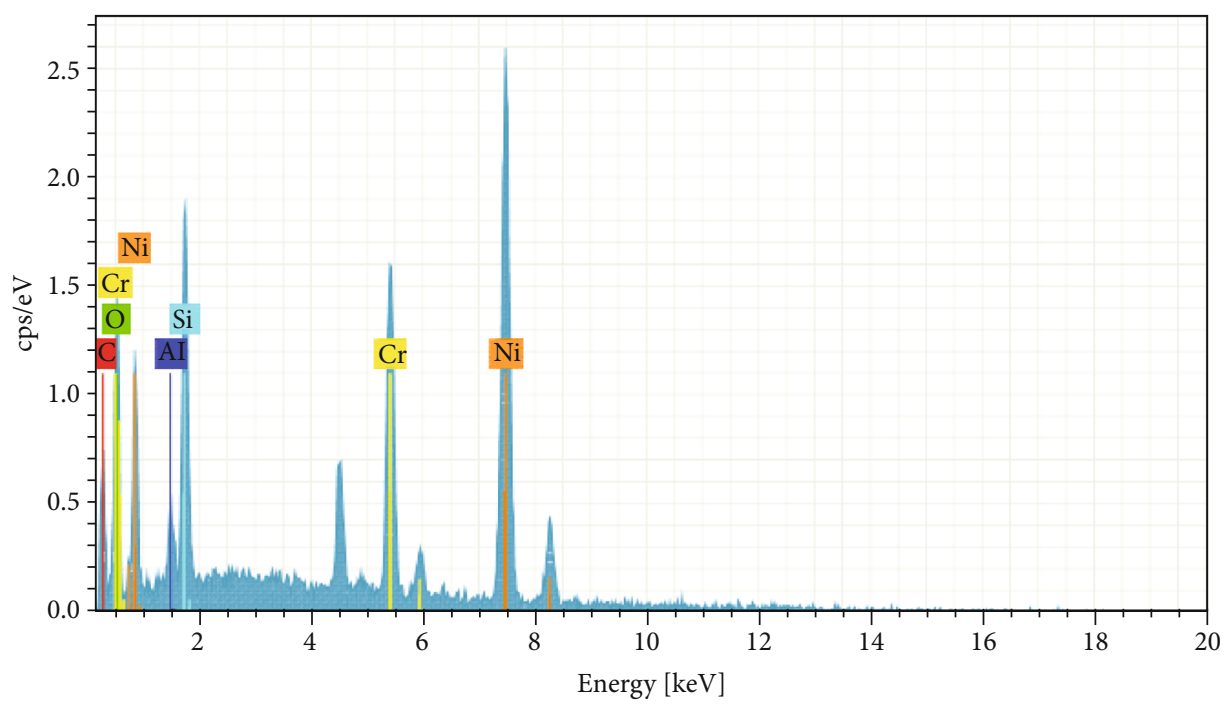

FIgURE 10: EDS for $0.3 \%$ volume concentration $\mathrm{Al}_{2} \mathrm{SiO}_{5}$.

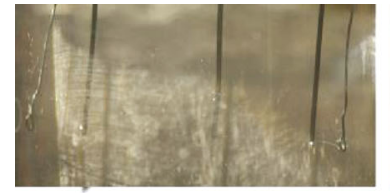

$63.5 \mathrm{~kW} / \mathrm{m}^{2}$

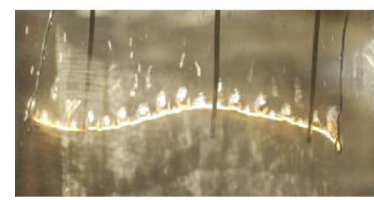

$1460 \mathrm{~kW} / \mathrm{m}^{2}$

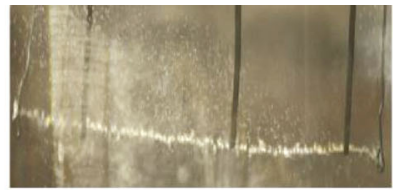

$222 \mathrm{~kW} / \mathrm{m}^{2}$

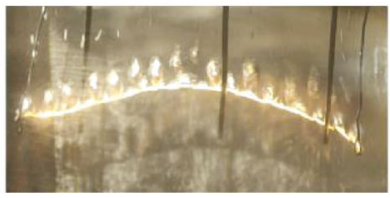

$1760 \mathrm{~kW} / \mathrm{m}^{2}$

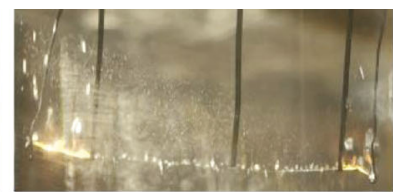

$553 \mathrm{~kW} / \mathrm{m}^{2}$

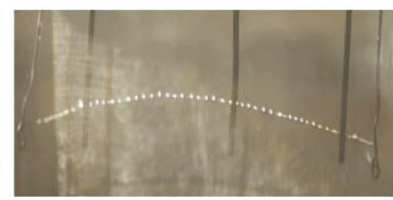

Burnout

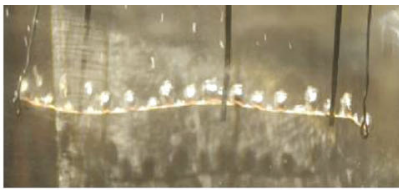

$1222 \mathrm{~kW} / \mathrm{m}^{2}$

Figure 11: Bubble diameter variation with increase in heat flux for water.

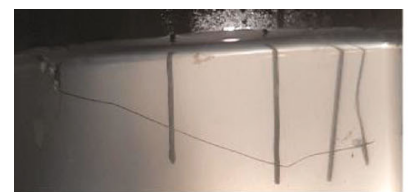

$240 \mathrm{~kW} / \mathrm{m}^{2}$

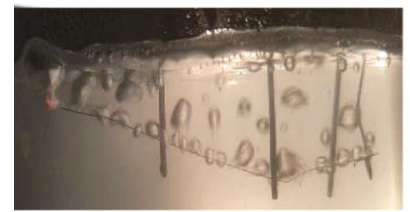

$1480 \mathrm{~kW} / \mathrm{m}^{2}$

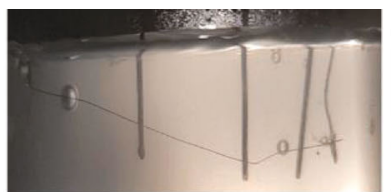

$420 \mathrm{~kW} / \mathrm{m}^{2}$

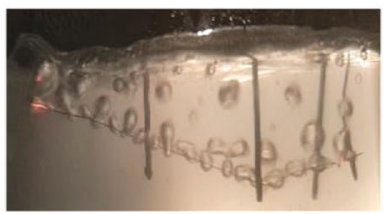

$1800 \mathrm{~kW} / \mathrm{m}^{2}$

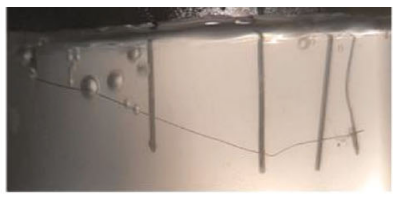

$675 \mathrm{~kW} / \mathrm{m}^{2}$

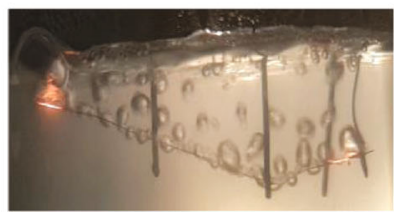

$2150 \mathrm{~kW} / \mathrm{m}^{2}$

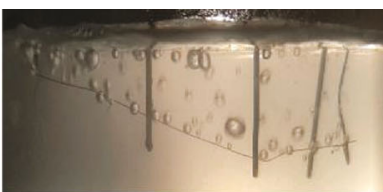

$1060 \mathrm{~kW} / \mathrm{m}^{2}$

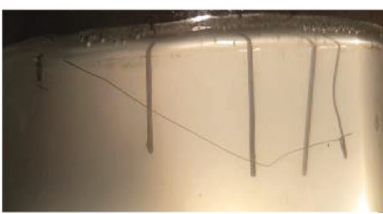

Burnout

FIGURE 12: Bubble diameter variation with increase in heat flux for $\mathrm{Al}_{2} \mathrm{SiO}_{5}$.

thermocouples. Similarly, the four thermocouples are equipped in beaker through the lid and all are placed at equal distance to determine the average wire temperature. Since thermocouples are placed too close to the surface, along with the minimal contact resistance of the tiny gap between the thermocouple tip and the wire surface, it is assumed that the measured temperature represents the boiling surface temperature. 
3.2. Experimental Procedure. Initially, the experiment is conducted in distilled water. The distilled water is heated on hot plate till its saturation temperature $T_{\text {sat }}$ is $100^{\circ} \mathrm{C}$, and temperature was being monitored by thermocouple. Current is applied to Ni-Chrome wire through platinum wires by regulating the variac. Voltage and ammeter readings are noted during burnout [9] of Ni-Chrome wire for heat flux measurement and for comparing with various nanofluids. Similarly, the nanofluid is heated on a hot plate to saturation temperature $T_{\text {sat }}\left(100^{\circ} \mathrm{C}\right)$ of base fluid (distilled water) at atmospheric pressure $1 \mathrm{~atm}$, while bulk temperature is monitored by thermocouples. Current is applied to NiChrome wire that is regulated by variac for constant heat flux control, with increments of $0.5 \mathrm{~A}$. The voltage measurements are noted at steady rate just after the current increase, and intervals are given after each increment to changes in system. Heat flux at any point is calculated by the following equation:

$$
q^{\prime \prime}=\frac{V I}{\pi D L}
$$

\section{Results and Discussion}

Figure 3(a) indicates presence of $\mathrm{OH}$ functional groups which might be due to the presence of moisture in the sample in the range around $3500 \mathrm{~cm}^{-1}$. The peak at $1100 \mathrm{~cm}^{-1}$ indicates the Si-O-Si antisymmetry stretching. Figure $3(\mathrm{~b})$ indicates no peaks which evidently shows the absence of organic compounds in the $\mathrm{CeO}_{2}$ nanoparticle.

4.1. XRD Analysis of $\mathrm{CeO}_{2}$. The crystal phase and the lattice constant of the nanocrystals were evaluated using XRD studies. Figures 4 and 5 show the XRD spectrum of the $\mathrm{KBr}$ mediated synthesis of $\mathrm{CeO}_{2}$ and $\mathrm{Al}_{2} \mathrm{SiO}_{5}$. The patterns in the figure $\mathrm{CeO}_{2}$, comprising peaks at the 2 theta values of 28.46, 32.96, 47.39, 56.23, 59.03, 69.27, 76.71, and 79.04,

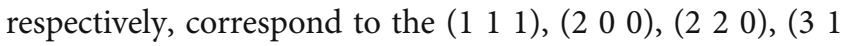
1), (2 2 2), ( (4 00 0), ( $\left.\begin{array}{lll}3 & 3 & 1\end{array}\right)$, and (4 20 ) planes, as depicted in Figure 4. All the diffraction patterns of $\mathrm{CeO}_{2}$ harmonized with the JCPDS data card No. 898436, and this shows the cubic crystal structure of $\mathrm{CeO}_{2}$ with a space group of Fm3m (225). In XRD patterns for $\mathrm{Al}_{2} \mathrm{SiO}_{5}$, the presence of moisture content of the sample showed a slight level of impurities in the prepared sample. No impurity peaks were observed indicating the high purity of the prepared samples. The existence of $\mathrm{CeO}_{2}$ was further identified by SEM and EDAX studies.

4.2. SEM and EDX Analysis. Scanning electron microscopy (SEM) is a unique technology to characterize the morphology, defects, and structure of materials. The typical SEM images in Figure 6 show the morphology of pure $\mathrm{Ni}$ Chrome wire, Figures 7(a), 8(a), and 9(a) show 0.1\%$0.3 \%$ of $\mathrm{Al}_{2} \mathrm{SiO}_{5}$-doped Ni-Chrome, and Figures $7(\mathrm{~b})$, $8(\mathrm{~b})$, and 9 (b) show $0.1 \%-0.3 \%$ of $\mathrm{CeO}_{2}$-doped $\mathrm{Ni}$ Chrome, respectively. It can be inferred from the SEM image in Figure 6 that pure Ni-Chrome wire has a smooth surface morphology as obtained while Figure 7(a) shows

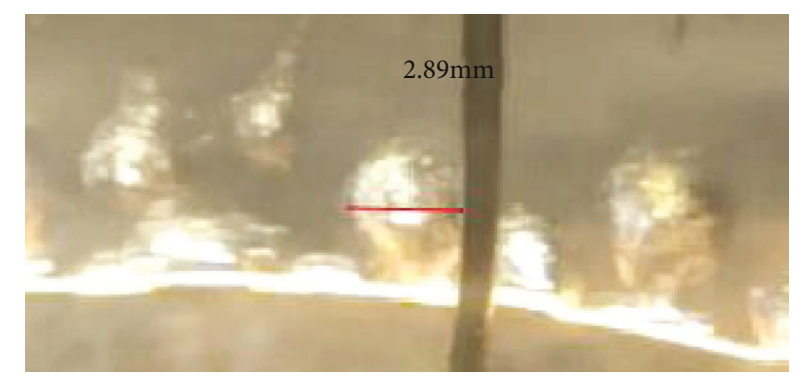

Figure 13: Bubble departure diameter for $\mathrm{Al}_{2} \mathrm{SiO}_{5}$ ( $0.3 \%$ vol) measured in Octave GNU.

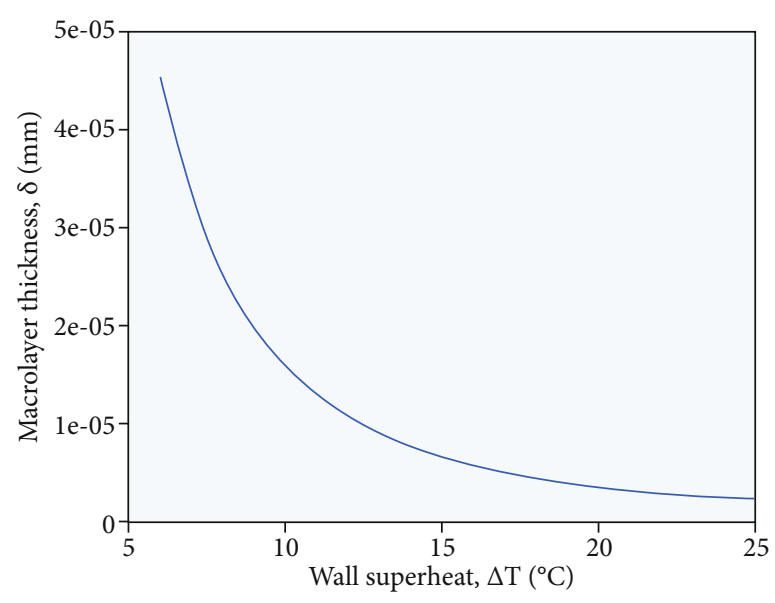

Figure 14: Heat flux variation with microlayer thickness.

the SEM images of $0.1 \%$ of $\mathrm{Al}_{2} \mathrm{SiO}_{5}$-doped Ni-Chrome; $\mathrm{Al}_{2} \mathrm{SiO}_{5}$ deposits are found on the Ni-Chrome wire, and with increasing concentration, there is a significant improvement observed. Figure 10 shows the elemental analysis of Ni-Chrome doped with $\mathrm{Al}_{2} \mathrm{SiO}_{5}$, in these compositions of $\mathrm{Ni}, \mathrm{Cr}, \mathrm{Si}, \mathrm{Al}$, and $\mathrm{O}$ that were present.

SEM imaging of Ni-Chrome wire-untreated (uncoated) was taken initially to study surface morphology and provide for a base to compare with wires used in experimentation. Figure 6 showcases a plain Ni-Chrome wire and can be seen to have no coatings and a simple plain structured morphology.

As noticed in Figures 7-9, a certain layer of coating tends to form on the wire during experimentation which clearly enhances the heat flux of wire as the excess heat dissipation due to this nanocoating [10] is enhanced when compared to uncoated wire and also becomes more efficient with increase in volume concentration of nanofluids; this is also evident in the respective EDS data as shown in Figure 10, which generated that with increase in volume concentration, the amount deposited onto the wire also increases.

The aluminum silicate and cerium oxide nanofluids were tested with the base-fluid water, and enhancements were observed that varied with change in volume fraction. The varying bubble diameter at increasing heat flux is portrayed in Figures 11 and 12 which show that the bubble diameter increases as the heat flux applied to the wire increases. 
TABle 2: Heat flux comparison to acclaimed studies.

\begin{tabular}{|c|c|c|}
\hline Model & Form & Value \\
\hline Zuber model & $q_{\max }^{\prime \prime}=0.131 h_{l v} \rho_{v}\left[\frac{\sigma\left(\rho_{l}-\rho_{v}\right) g}{\rho_{v}^{2}}\right]^{1 / 4}$ & $1.138 \times 10^{3} \mathrm{~W} / \mathrm{m}^{2}$ \\
\hline Rohsenow and Griffith bubble interface model & $q_{\text {max }}^{\prime \prime}=0.012 \rho_{g} h_{f g}\left(\frac{\rho_{f}-\rho_{g}}{\rho_{g}}\right)$ & $1.353 \times 10^{3} \mathrm{~W} / \mathrm{m}^{2}$ \\
\hline Haramura and Katto model & $q^{\prime \prime}{ }_{\max }=\rho_{f} h_{f g} \delta\left(1-0.0584\left(\frac{\rho_{g}}{\rho_{f}}\right)\right)$ & $1.286 \times 10^{3} \mathrm{~W} / \mathrm{m}^{2}$ \\
\hline This study & Experimental & $1.781 \times 10^{3} \mathrm{~W} / \mathrm{m}^{2}$ \\
\hline
\end{tabular}

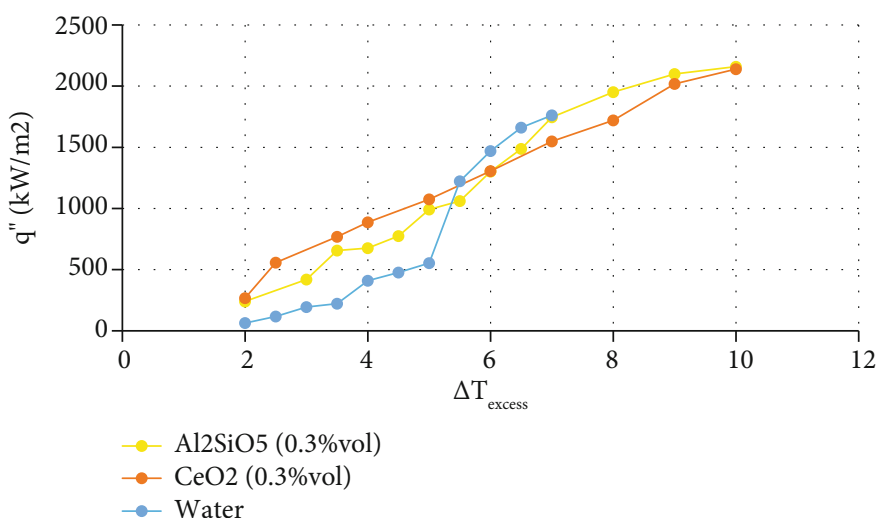

FIGURE 15: Heat flux comparison.

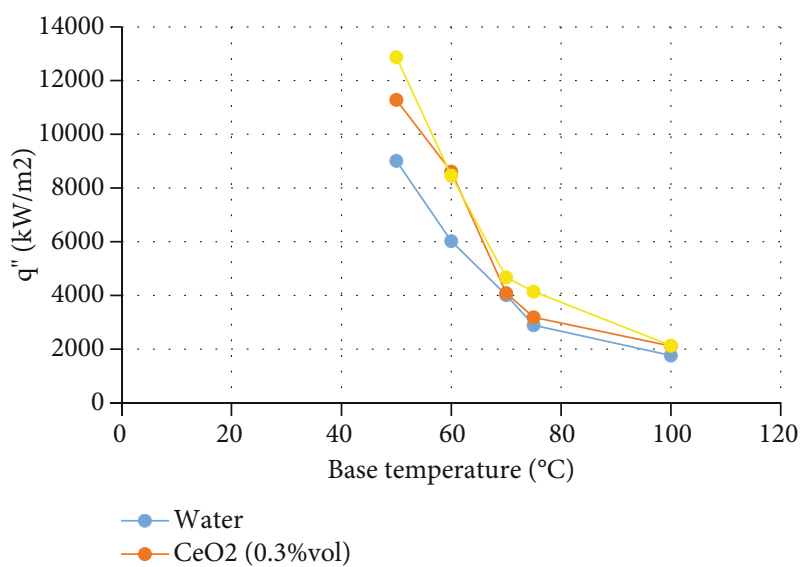

Figure 16: Heat flux variations based on base temperature.

It is observed that starting at lower base temperature, a higher value for peak heat flux can be achieved, as illustrated by the graph above. Theoretically, bubble diameter was calculated using Haramura relation.

Bubble departure diameter, $D_{b}$

$$
\sqrt{\frac{\sigma}{g\left(\rho_{l}-\rho_{g}\right)}}=2.77 \mathrm{~mm} \text { for water. }
$$

Experimentally, bubble diameter was calculated visually by using images captured during the experimentation process and using the Octave GNU software to attain exact values as shown in Figure 13.

Macrolayer thickness, $\delta$, was calculated by the following formula, $\delta(t)=\sqrt{\delta_{o}^{2}-2\left(\lambda \Delta T / \rho_{l} h_{f g}\right) t}$.

From the above formula, values where calculated using Octave GNU and it was inferred that the macrolayer thickness value decreases from the initial layer thickness as suggested by other literatures [11, 12], while an increase in initial macrolayer thickness is observed with increase in base temperatures for fluids. Graph in Figure 14 shows the values of macrolayer thickness varying with increase in wall superheat of fluid.

Use preestablished models where comparative study was done to determine variations with these and our experimental model [13]. Table 2 shows clear comparison of existing models for pool boiling.

Hence, from experimental data as shown in Figures 15 and 16, it is observed that both $\mathrm{Al}_{2} \mathrm{SiO}_{5}$ and $\mathrm{CeO}_{2}$ show enhancements of about $120.5 \pm 0.6 \%$ in PHF over water as base fluids for $0.3 \%$ volume concentration solutions. The reason for increase in PHF is also contributed by the macrolayer increase at higher temperatures [14]. Nucleation sites were determined using images captured from video taken during the experimentation process and were then fed into 


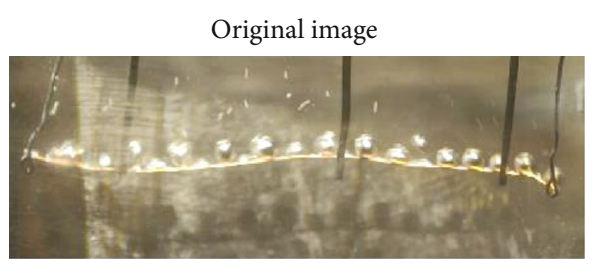

Binary image

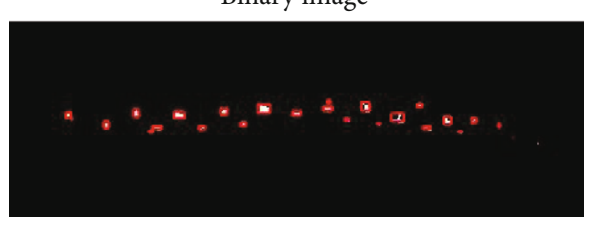

(a)
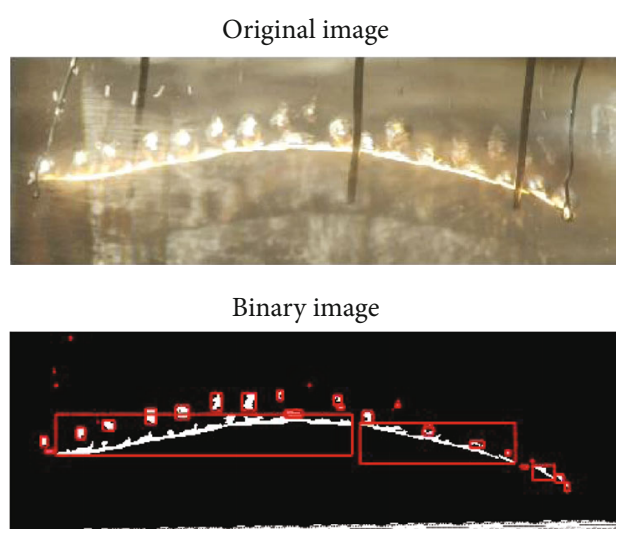

(b)

Figure 17: Nucleation sites on heater surface: (a) water and (b) water at higher PHF.

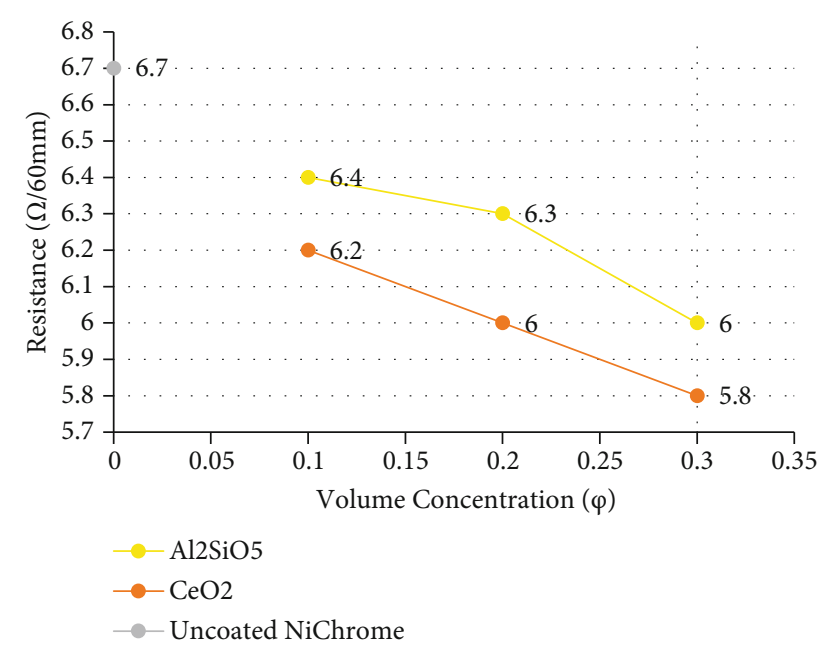

FIGURE 18: Influence of coating over Ni-Chrome wire on resistance of wire.

Octave GNU with algorithm created by author to determine number of sites as showcased in Figures 17(a) and 17(b).

Boiling has developed a great interest during the past few decades, as a method to increase the heat transfer rates with modest temperature differences. At high heat fluxes, heat transfer [15] by boiling is highly effective. Hence, find applications such coolants for nuclear reactors and also rocket engines where heat transfer rates are in high values $\left(10^{6}\right.$ to $\left.10^{7} \mathrm{~W} / \mathrm{m}^{2}\right)$. The probability to attain higher thermal energy conversion efficiency through boiling working fluid with heated surface is possible by these methodologies and has a large area of applications.

These coating of nanofluids over surface of wire or heater/heating surfaces tend to influence resistance which could be directly tracked to thermal conductance by inverse proportionality as shown in Figure 18 that when the coating increases, a decrease in resistance offered by wire is observed, and the values of resistance are for $60 \mathrm{~mm}$ of wire lengths as used in experimentation process for testing and generating direct relations. Nanofluids having high specific surface area serve to be better than other commercial fluids for heat transfer applications carrying more torridity between particles being the most important feature of nanofluids in heat carrying applications.

Using metallic fluids in heat carrying applications denotes significant difference when compared to commercial fluids for the same application. The hitch here being clogging of micrometer-sized particles in small passages and nanofluids being nanometer-sized can overcome this obstacle. Adding as low as 1-6 vol\% of nanoparticle in a base fluid can enhance the heat carrying ability to a significant change of $20 \%$. Usage of nanomaterials like $\mathrm{Cu}, \mathrm{Al}$, $\mathrm{Si}, \mathrm{Zn}, \mathrm{Mg}$, and $\mathrm{Se}$ is advised on this prospect, and so a combination of aluminum and silicate forming aluminum silicate $\left(\mathrm{Al}_{2} \mathrm{SiO}_{5}\right)$ and cerium oxide is tested upon with $0.1 \%, 0.2 \%$, and $0.3 \%$ of both the nanofluids. The stability of oxide-based nanofluids is higher, and therefore, both are chosen to be oxide-based nanofluids. Table 3 clearly depicts the improvement in peak heat flux (PHF) in comparison with other reported results.

Alumina particles have the tendency to decrease the pool boiling heat transfer but it has improved the CHF by $20 \%$ [20]. The CHF enhancement is due to the surface modifications that happen in the wire surface due to deposition of nanoparticles [21, 22]. A main cost attributing factor for nanofluids is the use of stabilizers which increases the production cost of these nanofluids without which nanoparticles tent to settle over a period of time. So cheaper stabilizers or nanofluids which are more substantial without the use of stabilizers need to be invented. The stabilizers that are commercially used in nanofluids are proven to be unstable at high temperatures being a drawback for stability in heat carrying applications. Most nanofluids upon testing results have lower specific heat at their respective temperatures when compared to its base fluids. On production of nanofluids, the particles tend to agglomerate into larger particles resulting in limiting the main asset of nanoparticles' high surface area. 
TABLE 3: Comparison with earlier literatures.

\begin{tabular}{lcc}
\hline Literature & Nanofluids & PHF \\
\hline Karima et al. [16], Liu et al. [17] & $\mathrm{CuO}$ in $\mathrm{H}_{2} \mathrm{O}$ & Enhanced by 25-50\% \\
Shi et al. [8] & $\mathrm{Al}_{2} \mathrm{O}_{3} \& \mathrm{Fe}$ in $\mathrm{H}_{2} \mathrm{O}$ & Enhanced to $\approx 60 \%$ \\
Wen et al. [5] & $\gamma-\mathrm{Al}_{2} \mathrm{O}_{3}$ in $\mathrm{H}_{2} \mathrm{O}$ & Enhanced to $\approx 40 \%$ \\
Milanova et al. [18] & $\mathrm{Al}_{2} \mathrm{O}_{3}, \mathrm{SiO}_{2}, \& \mathrm{CeO}_{2}$ in $\mathrm{H}_{2} \mathrm{O}$ & Deteriorated \\
Vassallo et al. [19] & $\mathrm{SiO}_{2}$ in $\mathrm{H}_{2} \mathrm{O}$ & Slight change \\
This study & $\mathrm{Al}_{2} \mathrm{SiO}_{5}, \mathrm{CeO}_{2}$ in $\mathrm{H}_{2} \mathrm{O}$ & Enhanced by $\approx 20 \%$ \\
\hline
\end{tabular}

\section{Conclusion}

In this study, the effects of nanoparticles in base-fluid water on heat transfer characteristics are conducted using a critical heat flux apparatus. The volume concentrations of $\mathrm{Al}_{2} \mathrm{SiO}_{5}$ and $\mathrm{CeO}_{2}$ nanofluids are varied from $0.1 \% \leq \varphi \leq 0.3 \%$. Readings taken at temperatures varied by $5^{\circ} \mathrm{C}$ between $50^{\circ} \mathrm{C}$ to $75^{\circ} \mathrm{C}$ and at $100^{\circ} \mathrm{C}$. The improvement of $q^{\prime \prime}$ for $\mathrm{Al}_{2} \mathrm{SiO}_{5} / \mathrm{H}_{2} \mathrm{O}$ and $\mathrm{CeO}_{2} / \mathrm{H}_{2} \mathrm{O}$ nanofluids is about $1.781 \times$ $10^{3} \mathrm{~W} / \mathrm{m}^{2}$, which displays a lower improvement in heat transfer for lower volume fraction; however, the significant enhancement of $q^{\prime \prime}$ is observed for higher volume fraction. From the results arrived, for enhancement of PHF and HTC nanofluids and nanosurface modifications showcase as dominant tools, modifications to working fluid and/or heater surface high thermal energy conversion efficiency can be achieved for boiling.

\section{Abbreviations}

$D_{b}: \quad$ Bubble departure diameter $(\mathrm{mm})$

$\sigma: \quad$ Surface tension $(\mathrm{N} / \mathrm{m})$

$g: \quad$ Gravity $\left(\mathrm{m} / \mathrm{s}^{2}\right)$

$\rho_{\mathrm{l}}: \quad$ Density of liquid $\left(\mathrm{kg} / \mathrm{m}^{3}\right)$

$\rho_{g}: \quad$ Density of vapor $\left(\mathrm{kg} / \mathrm{m}^{3}\right)$

$\delta: \quad$ Macrolayer thickness $(\mathrm{mm})$

$h_{f g}$ : Latent heat of vaporization $(\mathrm{kJ} / \mathrm{kg})$

$t: \quad$ Time (s

$q^{\prime \prime}$ : Heat flux $\left(\mathrm{W} / \mathrm{m}^{2}\right)$

$V: \quad$ Potential difference $(\mathrm{V})$

I: $\quad$ Input current (A)

$\pi D: \quad$ Circumference of Ni-Chrome wire $(\mathrm{m})$

$L: \quad$ Length of Ni-Chrome wire $(\mathrm{m})$

$\varphi$ : Volume concentration (\%)

$W_{n}$ : Weight of nanoparticle $(\mathrm{g})$

$\rho_{n}: \quad$ Bulk density of nanoparticle (g/cc)

$W_{b f}$ : Weight of base fluid (g)

$\rho_{\mathrm{bf}}: \quad$ Bulk density of base fluid (g/cc).

\section{Data Availability}

The data used to support the findings of this study are included within the article.

\section{Conflicts of Interest}

The authors declare that there is no conflict of interest regarding the publication of this article.

\section{Acknowledgments}

The authors acknowledge the HRTEM Facility at SRMIST setup with support from the Ministry of New and Renewable Energy India (Project No. 31/03/2014-15/PVSE-R\&D). We also acknowledge Nanotechnology Research Centre (NRC), SRMIST, for providing the research facilities. The authors are thankful for the financial support by the Researchers Supporting Project Number (RSP-2021/54), King Saud University, Riyadh, Saudi Arabia.

\section{References}

[1] S. Lee, S. U.-S. Choi, S. Li, and J. A. Eastman, "Measuring thermal conductivity of fluids containing oxide nanoparticles," Journal of Heat Transfer, vol. 121, no. 2, pp. 280-289, 1999.

[2] P. Vetrivezhan, C. Ayyanar, P. V. Arunraj, P. Vasanthkumar, and D. Ganesan, "Electroless deposition of aluminium alloy LM25 by SiC and Ni-P nano coating," Materials Today: Proceedings, vol. 45, pp. 6449-6453, 2021.

[3] K. Arul and V. S. Senthil Kumar, "Effects of Nano additives in bio cutting fluid for turning of Monel K500 alloy," Journal of the Balkan Tribological Association, vol. 26, no. 3, pp. 589$600,2020$.

[4] K. Arul and V. S. Senthil Kumar, "Magnetorhelogical based minimum quantity lubrication (MR-MQL) with additive n$\mathrm{CuO}, "$ Materials and Manufacturing Processes, vol. 35, no. 4, pp. 405-414, 2020.

[5] D. Wen and Y. Ding, "Experimental investigation into the pool boiling heat transfer of aqueous based $\gamma$-alumina nanofluids," Journal of Nanoparticle Research, vol. 7, no. 2-3, pp. 265-274, 2005.

[6] S. Das, D. S. Kumar, and S. Bhaumik, "Experimental study of nucleate pool boiling heat transfer of water on silicon oxide nanoparticle coated copper heating surface," Applied Thermal Engineering, vol. 96, pp. 555-567, 2016.

[7] S. Mukherjee and S. Paria, "Preparation and stability of nanofluids-a review," IOSR Journal of Mechanical and Civil Engineering, vol. 9, no. 2, pp. 63-69, 2013.

[8] M. H. Shi, M. Q. Shuai, Z. Q. Chen, Q. Li, and Y. M. Xuan, "Study on pool boiling heat transfer of nano-particle suspensions on plate surface," Journal of Enhanced Heat Transfer, vol. 14, no. 3, pp. 223-231, 2007. 
[9] T. G. Theofanous, T. N. Dinh, J. P. Tu, and A. T. Dinh, “The boiling crisis phenomenon: part II: dryout dynamics and burnout," Experimental Thermal and Fluid Science, vol. 26, no. 6-7, pp. 793-810, 2002.

[10] V. B. Khabensky, A. L. Sirotkina, V. I. Almjashev, E. D. Fedorovich, V. V. Sergeev, and V. V. Gusarov, "Experimental studies of impact on a critical heat flux the parameters of nanoparticle layer formed at nanofluid boiling," Nanosystems: Physics, Chemistry, Mathematics, vol. 9, no. 2, pp. 279-289, 2018.

[11] H. K. Forster and N. Zuber, "Dynamics of vapor bubbles and boiling heat transfer," AICHE Journal, vol. 1, no. 4, p. 531, 1955.

[12] Y. Haramura and Y. Katto, “Новая гидРодинамическая модель кРитического теплового потока, пРигодная для описания кипения как в Большом оБъеме, так и пРи вынузденной конвекции в случае тел, погРузенныч в насызенную зидкость," International Journal of Heat and Mass Transfer, vol. 26, no. 3, pp. 389-399, 1983.

[13] S. Nukiyama, "The maximum and minimum values of the heat Q transmitted from metal to boiling water under atmospheric pressure," Journal of the Society of Mechanical Engineers, vol. 37, no. 206, pp. 367-374, 1934.

[14] K. C. Udaiyakumar, U. Poongundran, K. Yoganand, and V. M. Kumar, "An experimental study and comparitive validation of macrolayer thickness in nucleate pool boiling for horizontal copper tube heater," IOP Conference Series: Materials Science and Engineering, vol. 402, 2018.

[15] X. Fang, Y. Chen, H. Zhang, W. Chen, A. Dong, and R. Wang, "Heat transfer and critical heat flux of nanofluid boiling: a comprehensive review," Renewable and Sustainable Energy Review, vol. 62, pp. 924-940, 2016.

[16] K. Boukerma and M. Kadja, "Convective heat transfer of $\mathrm{Al} 2 \mathrm{O} 3$ and $\mathrm{CuO}$ nanofluids using various mixtures of waterethylene glycol as base fluids," Engineering, Technology \& Applied Science Research, vol. 7, no. 2, pp. 1496-1503, 2017.

[17] Z. Liu, J. Xiong, and R. Bao, "Boiling heat transfer characteristics of nanofluids in a flat heat pipe evaporator with microgrooved heating surface," International Journal of Multiphase Flow, vol. 33, pp. 1284-1295, 2007.

[18] D. Milanova and R. Kumar, "Role of ions in pool boiling heat transfer of pure and silica nanofluids," Applied Physics Letters, vol. 87, no. 23, pp. 233107-233107-3, 2005.

[19] P. Vassallo, R. Kumar, and S. D. Amico, "Pool boiling heat transfer experiments in silica-water nano-fluids," International Journal of Heat and Mass Transfer, vol. 47, no. 2, pp. 407-411, 2004.

[20] I. C. Bang and S. H. Chang, "Boiling heat transfer performance and phenomena of $\mathrm{Al}_{2} \mathrm{O}_{3}$-water nano-fluids from a plain surface in a pool," International Journal of Heat and Mass Transfer, vol. 48, no. 12, pp. 2407-2419, 2005.

[21] H. S. Ahn and M. H. Kim, "The boiling phenomenon of alumina nanofluid near critical heat flux," International Journal of Heat and Mass Transfer, vol. 62, pp. 718-728, 2013.

[22] K. Arul and V. S. Senthil Kumar, "Effect of magneto rheological minimum quantity lubrication on machinability, wettability and tribological behavior in turning of Monel K500 alloy," International Journal of Machining Science and Technology, vol. 24, no. 5, pp. 810-836, 2020. 